J. Dairy Sci. 97:7185-7196

http://dx.doi.org/10.3168/jds.2014-8632

(C) American Dairy Science Association ${ }^{\circledR}, 2014$.

\title{
Using the Small Ruminant Nutrition System to develop and evaluate an alternative approach to estimating the dry matter intake of goats when accounting for ruminal fiber stratification
}

\author{
J. G. L. Regadas Filho, ${ }^{\star 1}$ L. O. Tedeschi,† A. Cannas,‡ R. A. M. Vieira,§ and M. T. Rodrigues* \\ *Departamento de Zootecnia, Universidade Federal de Viçosa, 36570 Minas Gerais, Brazil \\ †Department of Animal Science, Texas A\&M University, College Station 77843-2471 \\ ‡Dipartimento di Agraria, Sezione di Scienze Zootecniche, University of Sassari, 07100 Sassari, Italy \\ §Laboratório de Zootecnia e Nutrição Animal, Universidade Estadual do Norte Fluminense Darcy Ribeiro, Campos dos Goytacazes, \\ 28013-602 Rio de Janeiro, Brazil
}

\begin{abstract}
The first objective of this research was to assess the ability of the Small Ruminant Nutrition System (SRNS) mechanistic model to predict metabolizable energy intake (MEI) and milk yield (MY) when using a heterogeneous fiber pool scenario (GnG1), compared with a traditional, homogeneous scenario (G1). The second objective was to evaluate an alternative approach to estimating the dry matter intake (DMI) of goats to be used in the SRNS model. The GnG1 scenario considers an age-dependent fractional transference rate for fiber particles from the first ruminal fiber pool (raft) to an escapable pool $\left(\lambda_{r}\right)$, and that this second ruminal fiber pool (i.e., escapable pool) follows an age-independent fractional escape rate for fiber particles $\left(k_{e}\right)$. Scenario G1 adopted only a single fractional passage rate $\left(k_{p}\right)$. All parameters were estimated individually by using equations published in the literature, except for 2 passage rate equations in the G1 scenario: 1 developed with sheep data (G1-S) and another developed with goat data (G1-G). The alternative approach to estimating DMI was based on an optimization process using a series of dietary constraints. The DMI, MEI, and MY estimated for the GnG1 and G1 scenarios were compared with the results of an independent dataset $(\mathrm{n}=$ 327 ) that contained information regarding DMI, MEI, MY, and milk and dietary compositions. The evaluation of the scenarios was performed using the coefficient of determination $\left(\mathrm{R}^{2}\right)$ between the observed and predicted values, mean bias (MB), bias correction factor $\left(\mathrm{C}_{\mathrm{b}}\right)$, and concordance correlation coefficient. The
\end{abstract}

Received July 17, 2014.

Accepted August 8, 2014.

${ }^{1}$ Corresponding author: gilsonagro@yahoo.com.br
MEI estimated by the GnG1 scenario yielded precise and accurate values $\left(\mathrm{R}^{2}=0.82 ; \mathrm{MB}=0.21 \mathrm{Mcal} / \mathrm{d}\right.$; $\left.\mathrm{C}_{\mathrm{b}}=0.98\right)$ similar to those of the G1-S $\left(\mathrm{R}^{2}=0.85\right.$; $\left.\mathrm{MB}=0.10 \mathrm{Mcal} / \mathrm{d} ; \mathrm{C}_{\mathrm{b}}=0.99\right)$ and $\mathrm{G} 1-\mathrm{G}\left(\mathrm{R}^{2}=0.84\right.$; $\left.\mathrm{MB}=0.18 \mathrm{Mcal} / \mathrm{d} ; \mathrm{C}_{\mathrm{b}}=0.98\right)$ scenarios. The results were also similar for the MY, but a substantial MB was found as follows: $\mathrm{GnG} 1\left(\mathrm{R}^{2}=0.74 ; \mathrm{MB}=0.70\right.$ $\left.\mathrm{kg} / \mathrm{d} ; \mathrm{C}_{\mathrm{b}}=0.79\right), \mathrm{G} 1-\mathrm{S}\left(\mathrm{R}^{2}=0.71 ; \mathrm{MB}=0.58 \mathrm{~kg} / \mathrm{d}^{1}\right.$; $\left.\mathrm{C}_{\mathrm{b}}=0.85\right)$ and $\mathrm{G} 1-\mathrm{G}\left(\mathrm{R}^{2}=0.71 ; \mathrm{MB}=0.65 \mathrm{~kg} / \mathrm{d} ; \mathrm{C}_{\mathrm{b}}\right.$ $=0.82$ ). The alternative approach for DMI prediction provided better results with the G1-G scenario $\left(\mathrm{R}^{2}=\right.$ $\left.0.88 ; \mathrm{MB}=-71.67 \mathrm{~g} / \mathrm{d} ; \mathrm{C}_{\mathrm{b}}=0.98\right)$. We concluded that the GnG1 scenario is valid within mechanistic models such as the SRNS and that the alternative approach for estimating DMI is reasonable and can be used in diet formulations for goats.

Key words: heterogeneous fiber pool, nonlinear optimization, rumen capacity

\section{INTRODUCTION}

The nutritional value of ruminant feedstuffs depends on the retention time in the gastrointestinal tract, animal species, BW, DMI, and many other factors that can affect feedstuffs' availability and digestibility (Van Soest, 1994). The only way to evaluate the interactions between these variables is to use nonspecific and comprehensive methods. In response to this limitation, mechanistic nutrition models have been developed to predict different aspects of ruminant nutrition. The Small Ruminant Nutrition System (SRNS) (Cannas et al., 2007a; Tedeschi et al., 2010) is the most recent nutrition model for sheep and goats. The SRNS bases its logical calculation to predict the dietary supply of energy and nutrients on the Cornell Net Carbohydrate and Protein System (CNCPS) for cattle (Fox et al., 
2004) and sheep (Cannas et al., 2004). However, because the SNRS model is still under development, its modeling of goats under diverse production scenarios is not complete. Only one paper has evaluated lactating does with the SRNS (Cannas et al., 2007b), so additional evaluations with larger databases are needed to study the predictive power of the SRNS for goats.

Furthermore, most mathematical nutrition models currently in use include a submodel to predict DMI, but a range of factors that interact among each other determines changes in DMI. Theoretical and practical models that predict DMI based on the physical intake control theory have been proposed and tested (Illius and Gordon, 1991; Poppi et al., 1994; Forbes, 2007), but none of them have been evaluated in mechanistic models with the same ruminal modeling approach of the SRNS.

Vieira et al. (2008) proposed that DMI can be predicted by using an optimization process that includes typical constraints of ruminant diet formulation. If valid, this hypothesis may be an interesting tool for diet formulations and ruminant DMI predictions. This model would predict DMI with an approach more biologically sound than using DMI as a model input. Usually, the constraints that software adopts to formulate ruminant diets encompass nutritional requirements and nutritional constraints for avoiding dietary unbalances (e.g., an excess of NFC and fats). Extra constraints can be added to the optimization process to achieve physical fiber restrictions.

Another factor that can influence the physical aspects of intake control by ruminants is ruminal fiber stratification, which may occur when ruminants are fed considerable amounts of fiber (Sutherland, 1988). Equations used to estimate the fractional passage rate and fiber digestion in the SRNS model do not properly account for ruminal fiber stratification, so an evaluation of how to embed this approach into the SRNS model is necessary.

Thus, the objectives of this research were to evaluate the inclusion of a heterogeneous fiber pool approach in the SRNS model and to assess an alternative approach to predicting DMI for dairy goats.

\section{MATERIALS AND METHODS}

\section{Model Descriptions and General Assumptions}

A modified SRNS model (available in its original form at http://nutritionmodels.tamu.edu/srns.html, verified on June 26,2014 ) was used to evaluate a heterogeneous rumen fiber approach and mass fiber restrictions for goats. The SRNS uses the equations described by Tedeschi et al. (2010) to predict goat nutritional requirements, the CNCPS equations described by Fox et al. (2004), with modifications, in the calculation of fecal $\mathrm{CP}$, and the rate of passage equations of Cannas et al. (2004) to predict the dietary supply of energy and nutrients.

However, because of updates to the CNCPS model, we inserted the following modifications and assumptions in our assay.

(1) We included the modified predictions for ruminal $\mathrm{pH}$ and microbial growth (Tylutki et al., 2008), but we did not consider the submodel of FA absorption (Tylutki et al., 2008).

(2) Instead of using the new carbohydrate fractionation described by Lanzas et al. (2007), we assumed the original (Sniffen et al., 1992) 4 carbohydrate fractions: organic acids and sugars (CA), soluble fiber and starch (CB1), available insoluble fiber (CB2), and unavailable fiber fraction $(\mathbf{C C})$.

(3) We considered the heterogeneous pool scenario only for the fiber fraction $(\mathrm{CB} 2+\mathrm{CC})$; we considered the ruminal pool of all other feed fractions (carbohydrate and protein) to be homogeneous, and we calculated the ruminal digestibility (RD) using the linear, one-pool, age-independent steady-state approach: $R D=$ $k_{d} /\left(k_{d}+k_{p}\right)$, in which $\boldsymbol{k}_{d}$ and $\boldsymbol{k}_{p}$ are fractional rates of degradation and passage, respectively, but we calculated the $k_{p}$ used to estimate $\mathrm{RD}$ as the reciprocal of the total mean rumen retention time (TMRT).

(4) We adopted the $\mathrm{Ca}$ and $\mathrm{P}$ requirements as described by the AFRC (1993).

\section{Submodel for Estimating Passage Rate and Ruminal Fiber Digestibility}

The submodel described below is based on a heterogeneous ruminal fiber pool in goats receiving high-fiber diets and it considers general assumptions regarding particle flow as described by Matis (1972) and more recently by Vieira et al. (2008). These general assumptions include that the first ruminal fiber pool (raft) is governed by an age-dependent fractional transference rate of particles from the raft to an escapable pool $\left(\boldsymbol{\lambda}_{r}\right)$ and that this escapable fiber pool is governed by an age-independent fractional passage rate $\left(\boldsymbol{k}_{e}\right)$. The com- 
partmental mean residence time (CMRT) is calculated by using $\mathrm{CMRT}_{1}=N / \lambda_{r}$ and $\mathrm{CMRT}_{2}=1 / k_{e}$ for the first and second pools, respectively; $N$ represents the age-dependency order, which is an integer from the gamma function that governs the CMRT in the first ruminal pool. The TMRT is calculated as the sum of both pools' CMRT, and the passage rate $\left(k_{p}\right)$ is the reciprocal of the TMRT.

Based on these assumptions, Vieira et al. (2008) extended Waldo et al.'s (1972) original concept of the digestion and fill effects to account for a heterogeneous fiber pool in the rumen and recommended the equations below to predict the ruminal digestibility of the B2 carbohydrate fraction (Eq. [1]) and the filling effect of the fiber fraction (Eq. [2]):

$$
\begin{aligned}
R D C B 2_{j} & =D M I_{J} \times C B 2_{J} \\
& \times\left\{k_{d_{j}} \times\left[\sum_{i=1}^{N}\left[\frac{\lambda_{r_{j}}^{i-1}}{\left(\lambda_{r_{j}}+k_{d_{j}}\right)^{i}}\right]+\frac{\lambda_{r_{j}}^{N}}{\left[\left(\lambda_{r_{j}}+k_{d_{j}}\right)^{N}\left(k_{e_{i}}+k_{d_{i}}\right)\right]}\right]\right\},
\end{aligned}
$$

$$
\begin{aligned}
& Q_{\text {fiber }_{j}}= \\
& F C I_{j}\left\{\begin{array}{l}
\left.\frac{C B 2_{j}}{F C I_{j}} \times\left\{\sum_{i=1}^{N}\left[\frac{\lambda_{r_{j}}^{i-1}}{\left(\lambda_{r_{j}}+k_{d}\right)^{i}}\right]+\frac{\lambda_{r_{j}}^{N}}{\left[\left(\lambda_{r_{j}}+k_{d_{j}}\right)^{N}\left(k_{e_{j}}+k_{d_{j}}\right)\right]}\right]\right\}, \\
+\frac{C C_{j}}{F C I_{j}}\left[\frac{N}{\lambda_{r_{j}}}+\frac{1}{k_{e_{j}}}\right]
\end{array}\right\},
\end{aligned}
$$

where RDCB2 is the rumen-degraded B2 carbohydrate fraction (g), DMI is in grams/day, CB2 is the available insoluble fiber fraction in DM $(\mathrm{g} / \mathrm{kg}), k_{d}$ is the degradation rate for the $\mathrm{B} 2$ fraction, $Q_{f i b e r}$ is the rumen fiber mass per unit of intake (g), FCI is the fiber carbohydrate intake $(\mathrm{g} / \mathrm{d}), \mathrm{CC}$ is the unavailable fiber fraction in DM $(\mathrm{g} / \mathrm{kg})$, and subscript $j$ indicates each feed in the diet.

The age-dependent and age-independent rate parameters were estimated using the equations described by Regadas Filho et al. (2014) for forage and concentrate:

$$
N / \lambda_{r \text { For }}=0.358 \times \exp ^{\left[\begin{array}{l}
-0.0025 \times p e N D F I+0.0064 \times N D F_{\text {diet }} \\
+0.0133 \times\left(D M I / B W^{0.75}\right)
\end{array}\right],}
$$

$$
\begin{gathered}
k_{e \text { For }}=0.010 \times \exp ^{(-0.024 \times p e N D F I / B M)} \times L I G I^{0.476},[4] \\
N / \lambda_{r \text { Conc }}=81.43-9.98 \times \ln (D M I)+2.68 \times \ln \left(N / \lambda_{r F o r}\right),
\end{gathered}
$$

$k_{\text {eConc }}=0.274-0.0173 \times \ln (L I G I)+0.0448 \times \ln \left(k_{\text {eFor }}\right)$,

where $N / \lambda_{\text {rFor }}$ is the CMRT of the first ruminal pool for forage $(\mathrm{h}) ; k_{e F o r}$ is the fractional rate of particle escape from the escapable forage pool $\left(\mathrm{h}^{-1}\right) ; N / \lambda_{\text {rConc }}$ is the CMRT of the first ruminal concentrate pool (h); $k_{\text {eConc }}$ is the fractional rate of particle escape from the escapable pool for concentrate $\left(\mathrm{h}^{-1}\right)$; peNDFI is the intake of physically effective $\mathrm{NDF}(\mathrm{g} / \mathrm{d}) ; N D F_{\text {diet }}$ is the concentration of NDF in the diet $(\mathrm{g} / \mathrm{kg})$; DMI is in grams per day; $B W$ is in kilograms; and $L I G I$ is lignin intake $(\mathrm{g} / \mathrm{d})$.

Because the equations developed in Regadas Filho et al. (2014) predict CMRT $\left(N / \lambda_{r}\right)$, and because the equations used to predict RDCB2 and $Q_{\text {fiber }}$ also required the parameter itself $\left(\lambda_{r}\right)$, an indirect approach was used to assess it. It was assumed that the order of age dependency decreased as the rate of FCI $\left(F C I^{c}=F C I / B W\right)$ increased, and the following classes were used to obtain the estimated order of age dependency $\left(\boldsymbol{N}^{\prime}\right): \quad \forall F C I^{c}<5, N^{\prime}=3 ; 5 \leq \forall F C I^{c} \leq 12, N^{\prime}=2, \quad$ and $\forall F C I^{c}>12, N^{\prime}=1$ (Vieira et al., 2008).

The model used to address the heterogeneous (GnG1) fiber pool was compared with the traditional homogeneous (G1) fiber pool model to predict the ME intake (MEI) and to estimate the milk yield (MY) from dairy goats. The rumen passage rate in the homogeneous fiber pool model was calculated by using forage and concentrate equations developed by Cannas et al. (2004) for sheep (G1-S) [equations 43 and 44 in Cannas et al. (2004)]; the SRNS currently uses these equations. In addition, the equation developed by Tedeschi et al. (2012) to predict rumen forage rate passage in goats [G1-G; equation 9 in Tedeschi et al. (2012)] was evaluated. Because Tedeschi et al. (2012) did not develop an equation to predict concentrate passage rate, the equation developed for concentrate feeds by Cannas et al. (2004) was used. All evaluated scenarios (GnG1, G1-S, and G1G) used the equation described by Cannas et al. (2004) to estimate the rate of passage of liquids.

The rumen-filling effects in homogeneous fiber pool scenarios were calculated using the following expression (Waldo et al., 1972): 
$Q_{f i b e r_{j}}=F C I_{j} \times\left[\left(C B 2_{j} / F C I_{j}\right) /\left(k_{p_{j}}+k_{d_{j}}\right)+\left(C C_{j} / F C I_{j}\right) / k_{p_{j}}\right]$

where $C B 2$ is the available insoluble fiber fraction in DM $(\mathrm{g} / \mathrm{kg}), k_{d}$ is the degradation rate for the B2 fraction, $k_{p}$ is the passage rate of the feed, calculated with the G1-S or the G1-G approaches, $Q_{f i b e r}$ is the rumen fiber mass per unit of intake (g), $F C I$ is the fiber carbohydrate intake $(\mathrm{g} / \mathrm{d}), C C$ is the unavailable fiber fraction in DM $(\mathrm{g} / \mathrm{kg})$, and subscript $j$ indicates each feed in the diet.

\section{Rumen Fiber Restrictions and Predictions of DMI}

It is possible to use the $Q_{f i b e r}$ estimated by both approaches (homogeneous and heterogeneous ruminal fiber pools) to evaluate the hypothesis of Vieira et al. (2008) that DMI can be predicted by using inequality constraints during ruminant diet optimization, as explained below. In this approach, the DMI would not be a model input but rather would act as an output. For this purpose, the modified SRNS model was inserted into an Excel spreadsheet (Microsoft Corp., Redmond, WA), and dietary constraints based on previous nutritional assumptions were considered, as described in Equations [9] to [18]. The DMI was calculated as the sum of all optimized diet ingredients for each animal (n $=327$ ) in the 3 evaluated scenarios (G1-S, G1-G, and GnG1). This DMI prediction was compared with the equation adopted by the AFRC (1993) for goats:

$$
D M I=0.062 B W^{0.75}+0.305 M Y,
$$

where DMI is expressed in kilograms/day, BW is expressed in kilograms, and MY is expressed in kilograms/day.

The objective function specified by Eq. [9] minimizes the cost function, where $\mathrm{c}_{j}$ is the price of $j$ feed ingredients times their use (denoted $X_{j}$, in $\mathrm{g}$ ) in the optimal ration. Equation [9] was subjected to a series of constraints described in Equations [10] to [18]. The constraints represented in Equations [10] to [13] refer to the nutritional requirements of MEI, MP intake (MPI), $\mathrm{Ca}$ intake, and $\mathrm{P}$ intake. The subscript req indicates the requirement for a specific nutritional component. To allow more flexibility in the optimization process, the $p$ constant (ranging from 0 to 1 ) that represents the precision of the model was assumed to be 0.1 . In other words, a flexibility of $\pm 10 \%$ on each estimated parameter was accepted, so a ration was allowed to have up to $10 \%$ more or less of a particular nutritional entity (e.g., ME).

$$
D M I= \begin{cases}\text { MinimizeCost }=\sum_{j=1}^{n} c_{j} \times X_{j}, & {[9]} \\ \text { subject to : } & \\ (1-p) \times M E I_{\text {req }} \leq \sum_{j=1}^{n} M E I_{j} \leq(1+p) \times M E I_{\text {req }},[10] \\ (1-p) \times M P I_{\text {req }} \leq \sum_{j=1}^{n} M P I_{j} \leq(1+p) \times M P I_{\text {req }},[11] \\ {[1-p) \times C a_{\text {req }} \leq \sum_{j=1}^{n} C a_{j} \leq(1+p) \times C a_{\text {req }},}\end{cases}
$$

The constraints represented in Equations [14] to [16] refer to NFC $(\leq 42 \%)$, fat $(\leq 6 \%)$, and physically effective NDF $(\geq 20 \%)$ concentrations in dietary DM. The BactNBalance $(\mathrm{g} / \mathrm{d})$ in the constraint represented in Eq. [17] is an estimate of the rumen $\mathrm{N}$ balance, and it was used to avoid $\mathrm{N}$ excesses or limitations in the diet that would increase the maintenance energy requirement in relation to urea excretion or limitations to microorganism growth, respectively. Arbitrary bounds from 0 to $10 \mathrm{~g} / \mathrm{d}$ were assumed.

Equation [18] shows the constraint relating to ruminal fiber. The addition of $Q_{f i b e r}$ for each dietary component yields the average total amount of fiber present in the rumen. The limitation of this component is that the value has to be less than or equal to the ruminal capacity (g). Although the ruminal capacity has been reported to be scaled to unity in relation to BW (Demment and Van Soest, 1985), we used the equation described in Regadas Filho et al. (2014) to estimate the ruminal capacity as $6.89 \times \mathrm{BW}^{1.16}$. 
Table 1. Dataset summary ${ }^{1}$

\begin{tabular}{|c|c|c|c|c|}
\hline Item & Mean & $\mathrm{SD}$ & Minimum & Maximum \\
\hline \multicolumn{5}{|l|}{ Animal information } \\
\hline $\mathrm{BW}, \mathrm{kg}$ & 54.27 & 8.70 & 36.10 & 78.70 \\
\hline DMI, g/d & 1,939 & 523 & 666 & 3,451 \\
\hline $\mathrm{MY}, \mathrm{kg} / \mathrm{d}$ & 2.45 & 1.18 & 0.09 & 6.81 \\
\hline Milk fat content, $\%$ & 3.17 & 0.59 & 1.85 & 5.04 \\
\hline Milk protein content, $\%$ & 2.96 & 0.36 & 2.29 & 4.95 \\
\hline ME intake, Mcal/d & 5.02 & 1.32 & 1.53 & 8.21 \\
\hline \multicolumn{5}{|c|}{ Dietary information, $\mathrm{g} / \mathrm{kg}$ of DM } \\
\hline Forage & 415.10 & 19.06 & 205.22 & 941.46 \\
\hline Concentrate & 584.90 & 19.06 & 58.54 & 794.78 \\
\hline Ash & 63.83 & 1.52 & 38.37 & 104.76 \\
\hline $\mathrm{CP}$ & 172.78 & 2.01 & 116.92 & 225.19 \\
\hline Fat & 26.50 & 1.16 & 14.20 & 66.11 \\
\hline Total carbohydrate & 741.82 & 2.39 & 690.52 & 814.44 \\
\hline NFC & 382.19 & 11.20 & 77.51 & 654.71 \\
\hline Fiber carbohydrate & 359.63 & 10.37 & 235.43 & 654.71 \\
\hline
\end{tabular}

${ }^{1}$ Dataset comprised 10 studies with 45 treatments for a total of 327 individual measures in lactating dairy goats.

The nonlinear generalized reduced gradient method (Lasdon et al., 1974), available in Excel version 2010 (Microsoft Corp.), was used to optimize the diets. A precision of 0.001 was adopted, and the central derivatives method was used to estimate the partial derivatives of the objectives and constraint functions.

\section{Model Evaluation}

The dataset used to evaluate these scenarios was composed of 10 studies with 45 treatments for a total of 327 individual measures in lactating dairy does (Alpine and Saanen) in the Universidade Federal de Viçosa (Brazil), where DMI, MEI, MY, BW, and milk composition and dietary composition were measured. The MEI (Mcal/d) and MY (kg/d) were used to evaluate these scenarios. The MY was calculated from the first-limiting nutrient (ME or MP); that is, assuming that all energy or protein supply in excess of maintenance costs would be used for milk production. Table 1 summarizes this dataset.

Complete information regarding the concentrations of different fractions (carbohydrates and proteins) in the diets and their respective degradation rates was not available; however, some of them could be calculated from feed chemical analyses. Fraction CC of the carbohydrates was calculated as ADL $\times 2.4, \mathrm{CB} 2$ was calculated as $N D F_{j}-C C_{j}$, and protein fractions B3 and $\mathrm{C}$ were obtained from the neutral detergent fiber insoluble protein and acid detergent fiber insoluble protein analysis available in all experiments. The concentration of fractions $\mathrm{CA} 1$ and $\mathrm{CB} 1$ in carbohydrates; A1, B1, and $\mathrm{B} 2$ in proteins; and the degradation rates of all fractions were obtained from the tropical feed library in the original SRNS model.
The model evaluation was conducted using assumptions described by Tedeschi (2006). The precision of the models was assessed using the coefficient of determination $\left(\mathrm{R}^{2}\right)$ between the predicted and observed values in addition to the simultaneous $F$-test of the intercept and slope $\left(\mathrm{H}_{0}\right.$ : intercept $=0$ and slope $\left.=1 ; \alpha=0.05\right)$, whereas the accuracy was calculated based on the bias correction factor $\left(\mathbf{C}_{\mathbf{b}}\right)$, which indicates how far the regression line deviates from the slope of unity $\left(45^{\circ}\right)$; the concordance correlation coefficient $(\mathbf{C C C})$, mean bias (MB, observed - predicted), and root of mean square error prediction (RMSEP) and its decomposition into mean bias, systematic bias, and random errors were also calculated. Evaluations were performed by Model Evaluation System software (available at http:// nutritionmodels.tamu.edu/mes.html, verified June 26, 2014).

\section{RESULTS}

\section{MEI and MY Estimation}

Table 2 presents the parameters for MEI evaluation, and panels a, b, and $\mathrm{c}$ in Figure 1 show the linear regression between the observed and predicted values for the G1-S, G1-G, and GnG1 scenarios, respectively. Despite the simultaneous $F$-test rejecting a hypothesis in which the intercept $=0$ and slope $=1$ for the 3 assessed scenarios, all of them had high precision, as indicated by the high $\mathrm{R}^{2}=0.85,0.84$, and 0.82 for the G1-S, G1-G, and GnG1 approaches, respectively. A slight underprediction of the MEI was found; the G1-S scenario presented a lower $\mathrm{MB}(\mathrm{MB}=0.1028 \mathrm{Mcal} / \mathrm{d})$, but the $\mathrm{MB}$ values were not significant in all scenarios $(P=0.3616,0.1110$, and 0.0611 for the G1-S, G1-G, and GnG1 approaches, respectively). All scenarios pre- 
sented high accuracy $\left(\mathrm{C}_{\mathrm{b}}=0.99,0.98\right.$, and 0.98 for the G1-S, G1-G, and GnG1 approaches, respectively). All 3 CCC and RMSEP estimates were also similar (values in Table 1). The RMSEP decomposition showed that random errors were the main component of the error for all scenarios.

Table 3 presents the parameters of the MY evaluation, and panels d, e, and $\mathrm{f}$ in Figure 1 show the linear regression between the observed and predicted values for the G1-S, G1-G, and GnG1 scenarios, respectively. The MY evaluation yielded poorer results than the MEI evaluation. The simultaneous $F$-test for the intercept and slope rejected $\mathrm{H}_{0}$ for the studied scenarios, and their precisions were also similar, with a slight advantage for the GnG1 scenario $\left(\mathrm{R}^{2}=0.74\right)$. The models underestimated the MY. The MB were $0.58,0.65$, and $0.70 \mathrm{~kg} / \mathrm{d}$ for the G1-S, G1-G, and GnG1 scenarios, and all of them were significant $(P<0.0001)$. These $\mathrm{MB}$ had important effects on the RMSEP partition, contributing approximately $50 \%$ of the error decomposition. The remaining $50 \%$ was mostly explained by random error. The CCC is a measure of model accuracy and precision and supports the idea that the MY estimation was inferior to the MEI estimation.

\section{Evaluation of the DMI Estimation}

The optimization technique is an interesting tool for addressing DMI in ruminants; however, the complexity of the model and the interdependence of some variables did not allow all runs to reach a solution. Approximately $45 \%$ of the individual runs in each scenario reached a solution.
Table 4 shows the DMI evaluation parameters and Figure 2 shows a linear regression between observed and predicted values for the G1-S, G1-G, GnG1, and AFRC (AFRC, 1993) scenarios. When used with this optimization technique, the scenarios yielded higher precision (G1-S, R ${ }^{2}=0.85$; G1-G, $\mathrm{R}^{2}=0.88$; and GnG1, $R^{2}=0.83$ ) than the empirical equation (AFRC equation, $\left.\mathrm{R}^{2}=0.78\right)$. The G1-S scenario yielded inferior values of $\mathrm{MB}(\mathrm{MB}=-4.75 \mathrm{~g} / \mathrm{d}, P=0.9185)$, but all other evaluated scenarios slightly overpredicted DMI, as indicated by the negative MB (G1-G, MB = $-71.67 \mathrm{~g} / \mathrm{d}, P=0.1095 ; \mathrm{GnG} 1, \mathrm{MB}=-89.65 \mathrm{~g} / \mathrm{d}, P$ $=0.0598 ;$ and AFRC, $\mathrm{MB}=-46.19 \mathrm{~g} / \mathrm{d}, P=0.2013)$, although none of them were significant. The accuracy of the models was high $\left(\mathrm{C}_{\mathrm{b}} \approx 0.95\right.$ to 0.98$)$. The G1-G scenario yielded higher CCC (0.98) and inferior RMSEP $(228.29 \mathrm{~g} / \mathrm{d})$. A different pattern was observed here than for the MEI and MY evaluations, which produced the same pattern of RMSEP decomposition. For the G1-S and GnG1 scenarios, the systematic bias (42.2 and $43.81 \%$, respectively) and random errors (57.77 and $47.72 \%$, respectively) were of similar importance, whereas in the G1-G and AFRC (1993) scenarios, the random error ( 60.72 and $88.84 \%$, respectively) was the main component.

\section{DISCUSSION}

\section{MEI and MY Estimation}

The evaluated scenarios had similar power to predict goat MEI. The SRNS model was able to predict the MEI independently of the 3 sets of equations used to

Table 2. Parameters for evaluating the metabolizable energy intake (MEI) of different scenarios ${ }^{1}$

\begin{tabular}{lccc}
\hline & \multicolumn{3}{c}{ MEI $^{3}(\mathrm{Mcal} / \mathrm{d})$} \\
\cline { 2 - 4 } Parameter $^{2}$ & $\mathrm{G} 1-\mathrm{S}$ & $\mathrm{G} 1-\mathrm{G}$ & $\mathrm{GnG}$ \\
\hline Mean value predicted (Mcal/d) & 4.92 & 4.85 & 4.82 \\
$\mathrm{R}^{2}$ & 0.85 & 0.84 & 0.82 \\
$P$-value & $<0.0001$ & $<0.0001$ & $<0.0001$ \\
$\alpha=0$ and $\beta=1$ & & & \\
Mean bias & 0.1028 & 0.1763 & 0.2088 \\
$P$-value & 0.3616 & 0.1110 & 0.0611 \\
$\mathrm{C}_{\mathrm{b}}$ & 0.99 & 0.98 & 0.98 \\
CCC & 0.91 & 0.90 & 0.89 \\
RMSEP & 0.6083 & 0.6201 & 0.6731 \\
MB (\%) & 2.82 & 8.08 & 9.62 \\
SB (\%) & 25.58 & 20.26 & 21.76 \\
RE (\%) & 71.60 & 71.66 & 68.62 \\
\hline
\end{tabular}

${ }^{1} \mathrm{G} 1-\mathrm{S}=$ scenario using the equations developed by Cannas et al. (2004); G1-G = scenario using the equation developed by Tedeschi et al. (2012); and GnG1 = scenario using the equations developed by Regadas Filho et al. (2014).

${ }^{2} \alpha$ and $\beta$ are the intercept and slope of the linear equation between observed and predicted values; $\mathrm{C}_{\mathrm{b}}=$ bias correction factor; $\mathrm{CCC}=$ concordance correlation coefficient; RMSEP = root mean square error of prediction and its decomposition into $\mathrm{MB}=$ mean bias, $\mathrm{SB}=$ systematic bias, and $\mathrm{RE}=$ random error.

${ }^{3}$ Mean value observed $=5.03 \mathrm{Mcal} / \mathrm{d}$. 

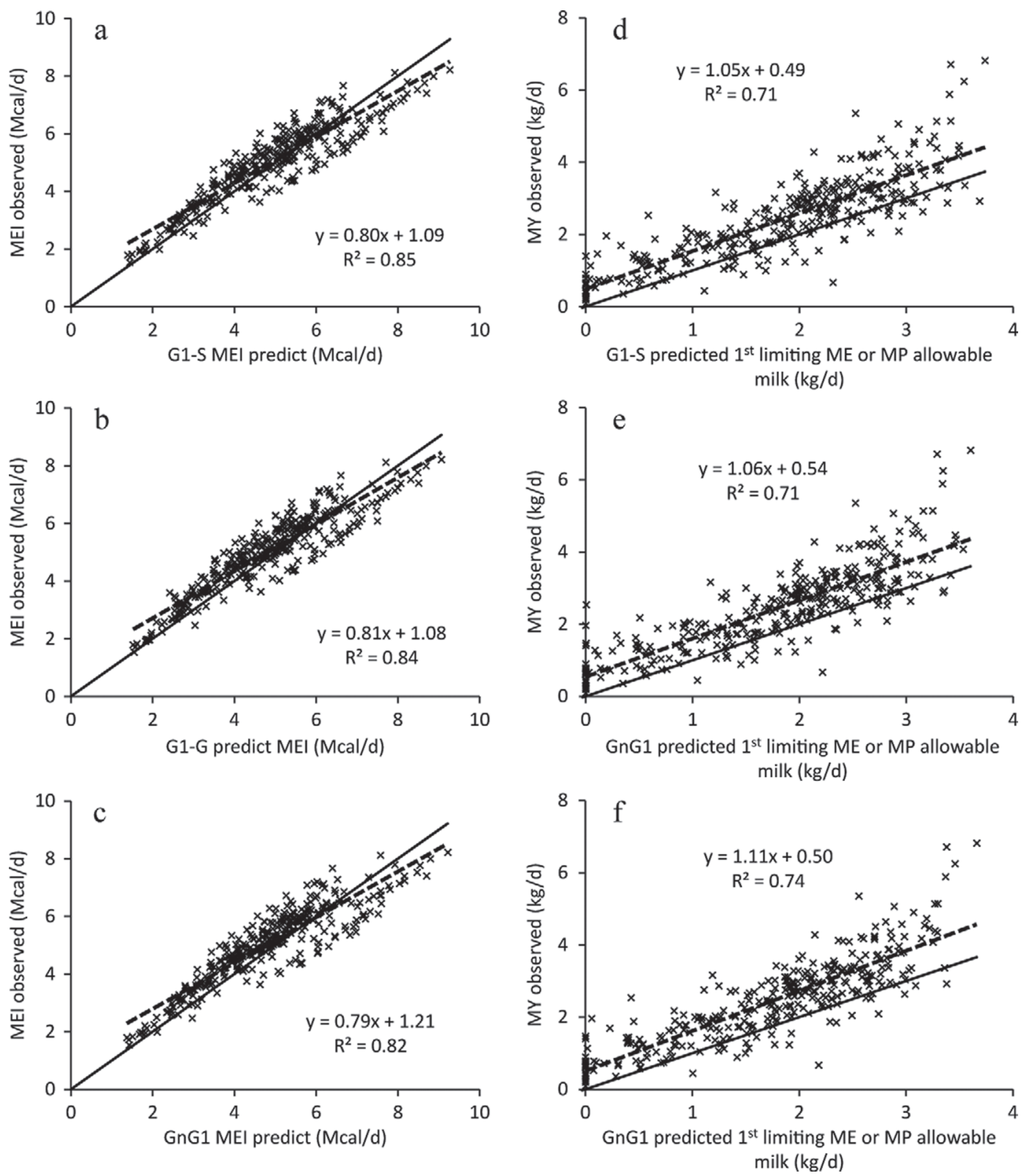

Figure 1. Linear regression between ME intake (MEI, Mcal/d; panels a, b, c) observed and predicted, and between milk yields (MY, kg/d) (panels d, e, f) observed and predicted by the G1-S (panels a, d), G1-G (panels b, e), and GnG1 (panels c, f) scenarios. G1-S = scenario using the equations developed by Cannas et al. (2004); G1-G = scenario using the equation developed by Tedeschi et al. (2012); and GnG1 = scenario using the equations developed by Regadas Filho et al. (2014).

estimate the passage rate. This outcome suggested that the model is either not very sensitive to variations in passage rate or that all equations estimated similar values for the rate of passage. The second hypothesis is likely because the 3 distributions were similar with a high degree of overlap (Figure 3). Cannas et al. (2007b) also found high accuracy and precision of the SRNS in predicting MEI and ME balance for lactating does by using the original passage rate equations, as described by Cannas et al. (2004), in the SRNS.
One could interpret the higher participation of the random error component in the RMSEP decomposition in the MEI evaluation as meaning there is a need for further studies to identify possible effects that were not controlled and may be influencing the results. One possible factor is that the $\mathrm{A} 1$ and $\mathrm{B} 1$ fractions and the degradation rates of all carbohydrate and protein feed fractions were not measured; rather, they were adopted from a tabular dataset, which could affect prediction values. It is extremely important to perform evalua- 
Table 3. Parameters for evaluating milk yield (MY) from different scenarios ${ }^{1}$

\begin{tabular}{lccc}
\hline & & $\mathrm{MY}^{3}(\mathrm{~kg} / \mathrm{d})$ & \\
\cline { 2 - 4 } Parameter $^{2}$ & G1-S & G1-G & GnG1 \\
\hline Mean value predicted $(\mathrm{kg} / \mathrm{d})$ & 1.87 & 1.80 & 1.76 \\
$\mathrm{R}^{2}$ & 0.71 & 0.71 & 0.74 \\
$P$-value & $<0.0001$ & $<0.0001$ & $<0.0001$ \\
$\alpha=0$ and $\beta=1$ & & & 0.70 \\
Mean bias & 0.58 & 0.65 & $<0.0001$ \\
$P$-value & $<0.0001$ & $<0.0001$ & 0.79 \\
$\mathrm{C}_{\mathrm{b}}$ & 0.85 & 0.82 & 0.68 \\
CCC & 0.72 & 0.69 & 0.9290 \\
RMSEP & 0.8616 & 0.9120 & 56.41 \\
MB (\%) & 45.68 & 50.74 & 1.16 \\
SB (\%) & 0.31 & 0.39 & 42.43 \\
RE (\%) & 54.01 & 48.87 & \\
\hline
\end{tabular}

${ }^{1}$ G1-S = scenario using the equations developed by Cannas et al. (2004); G1-G = scenario using the equation developed by Tedeschi et al. (2012); and GnG1 = scenario using the equations developed by Regadas Filho et al. (2014).

${ }^{2} \alpha$ and $\beta$ are the intercept and slope of the linear equation between observed and predicted values; $\mathrm{C}_{\mathrm{b}}=$ bias correction factor; $\mathrm{CCC}=$ concordance correlation coefficient; RMSEP $=$ root mean square error of prediction and its decomposition into $\mathrm{MB}=$ mean bias, $\mathrm{SB}=$ systematic bias, and $\mathrm{RE}=$ random error.

${ }^{3}$ Mean value observed $=2.45 \mathrm{~kg} / \mathrm{d}$.

tions on these types of models by using real values for feed fractions and degradation rates.

As in the predictions for MEI, the 3 evaluated scenarios showed essentially the same power of prediction for MY. However, the MY prediction had a significant MB (mean of $0.64 \mathrm{~kg} / \mathrm{d}$ ). This underprediction of MY is most likely explained by a lack of information regarding changes in goat BW in the dataset. This information could be used to estimate the ME available for MY from mobilization of body reserves using the submodel of energy and protein reserves present in SRNS.
It is likely that a significant portion of the animals were in negative energy balance. In this case, their milk production would be partly based on mobilized body reserves. In terms of evidence, we can demonstrate the effect of not addressing energy and protein body mobilization in the model. We can assume a nominal BW loss of $1 \mathrm{~kg} /$ wk during the first 4 wk of lactation; considering the $5.71 \mathrm{Mcal} / \mathrm{kg}$ for goat BW (AFRC, 1993), this parameter would yield $0.82 \mathrm{Mcal} / \mathrm{d}$ of body energy loss, and if we assume a 0.84 efficiency for mobilized tissue energy use (NRC, 2007), the energy allowable

Table 4. Parameters for evaluating the DMI of different scenarios ${ }^{1}$

\begin{tabular}{lcccc}
\hline & \multicolumn{4}{c}{$\mathrm{DMI}^{3}(\mathrm{~g} / \mathrm{d})$} \\
\cline { 2 - 5 } Parameter $^{2}$ & $\mathrm{G} 1-\mathrm{S}$ & $\mathrm{G} 1-\mathrm{G}$ & $\mathrm{GnG}$ & AFRC \\
\hline Mean value predicted $(\mathrm{g} / \mathrm{d})$ & $1,943.81$ & $2,010.73$ & $2,028.71$ & $1,985.25$ \\
$\mathrm{R}^{2}$ & 0.85 & 0.88 & 0.83 & 0.78 \\
$P$-value & $<0.0001$ & $<0.0001$ & $<0.0001$ & $<0.0001$ \\
$\alpha=0$ and $\beta=1$ & & & & \\
Mean bias & -4.75 & -71.67 & -89.65 & -46.19 \\
$P$-value & 0.9185 & 0.1095 & 0.0598 & 0.2013 \\
C $_{\mathrm{b}}$ & 0.97 & 0.98 & 0.95 & 0.95 \\
CCC & 0.89 & 0.92 & 0.87 & 0.84 \\
RMSEP & 266.40 & 228.29 & 307.95 & 258.29 \\
MB (\%) & 0.03 & 9.85 & 8.47 & 3.20 \\
SB (\%) & 42.20 & 29.43 & 43.81 & 7.96 \\
RE (\%) & 57.77 & 60.72 & 47.72 & 88.84 \\
\hline
\end{tabular}

${ }^{1} \mathrm{G} 1-\mathrm{S}=$ scenario using the equations developed by Cannas et al. (2004); G1-G = scenario using the equation developed by Tedeschi et al. (2012); and GnG1 = scenario using the equations developed by Regadas Filho et al. (2014); AFRC = values predicted using the equation of AFRC (1993).

${ }^{2} \alpha$ and $\beta$ are the intercept and slope of the linear equation between observed and predicted values; $\mathrm{C}_{\mathrm{b}}=$ bias correction factor; $\mathrm{CCC}=$ concordance correlation coefficient; RMSEP = root mean square error of prediction and its decomposition into $\mathrm{MB}=$ mean bias, $\mathrm{SB}=$ systematic bias, and $\mathrm{RE}=$ random error.

${ }^{3}$ Mean value observed $=1,936.06 \mathrm{~g} / \mathrm{d}$. 

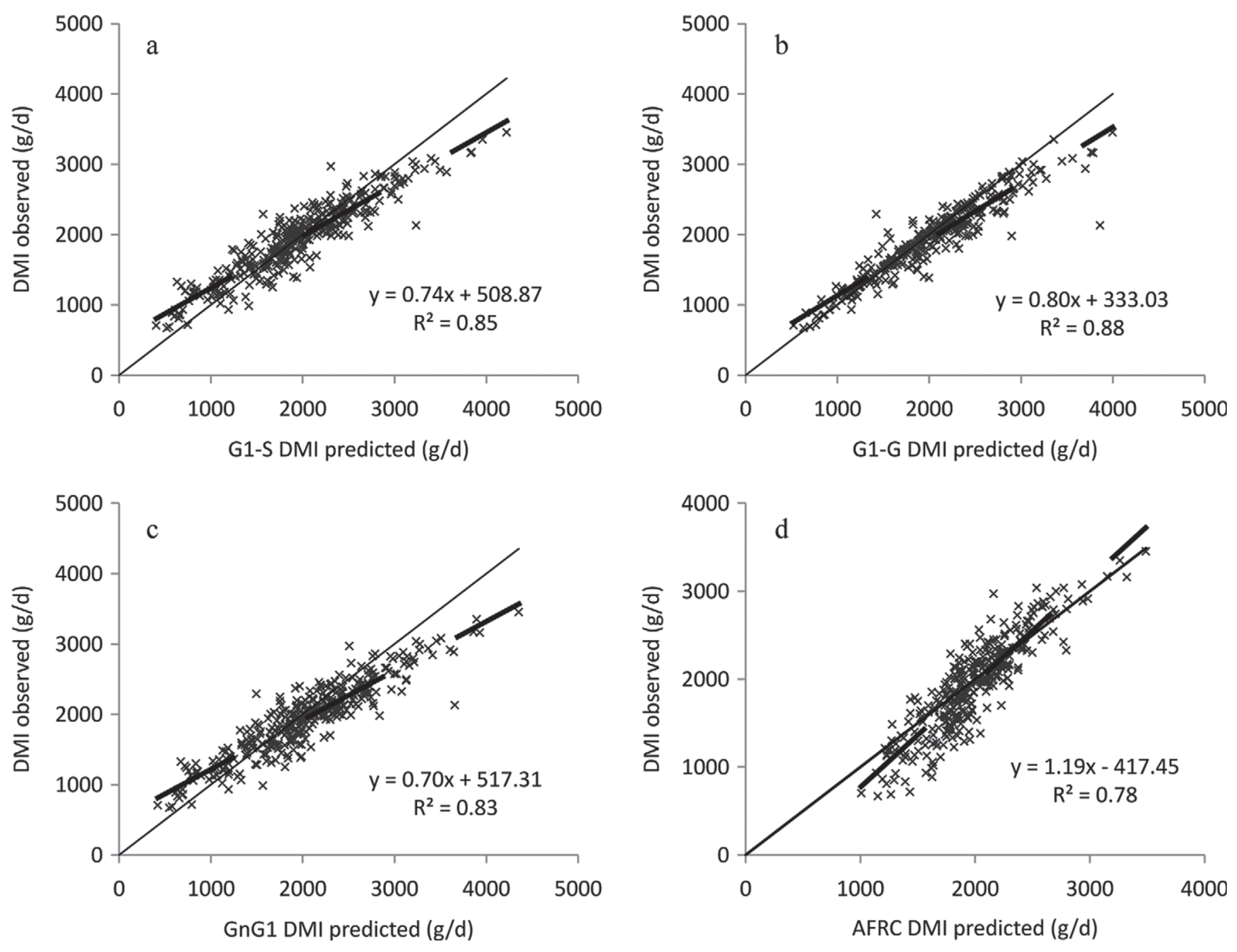

Figure 2. Linear regression between the DMI (g/d) observed and predicted by the G1-S (panel a), G1-G (panel b), GnG1 (panel c), and AFRC (panel d) scenarios. G1-S = scenario using the equations developed by Cannas et al. (2004); G1-G = scenario using the equation developed by Tedeschi et al. (2012); and GnG1 = scenario using the equations developed by Regadas Filho et al. (2014); AFRC = values predicted using the equation of AFRC (1993).

for milk production would be $0.68 \mathrm{Mcal} / \mathrm{d}$. The average milk concentration of fat and protein reported in the dataset was 3.17 and $2.96 \%$ (Table 1), respectively, which would yield an energy content of approximately $0.66 \mathrm{Mcal} / \mathrm{kg}$ of milk. The MB found in the analysis was $0.64 \mathrm{~kg} / \mathrm{d}$ of milk, and so $0.42 \mathrm{Mcal} / \mathrm{d}$, which is not very different from the $0.68 \mathrm{Mcal} / \mathrm{d}$ allowable for milk production. The slight difference of $0.26 \mathrm{Mcal} / \mathrm{d}$ is most likely caused by variation in BW loss. The $1 \mathrm{~kg} / \mathrm{wk}$ assumed here is for the initial 4 wk of lactation; we had 6 experiments starting at $60 \mathrm{~d}$ after kidding, 1 experiment starting at $45 \mathrm{~d}$ after kidding, and 1 experiment starting at $28 \mathrm{~d}$ after kidding, whereas 2 experiments did not report this information in the dataset. Thus, the animals were most likely losing less than $1 \mathrm{~kg} / \mathrm{wk}$.
Moreover, we only considered the energy allowable for milk production, but the MP available for milk production is also an important factor. Tylutki et al. (2008) reported that the MP was the first-limiting nutrient for all dairy cows' diets examined.

These results indicate that both homogeneous (G1$\mathrm{S}$ and G1-G) and heterogeneous (GnG1) fiber pool approaches have similar robustness for predicting the MEI and MY of goats. If we consider only the principle of parsimony, we would adopt the simplest approach (homogeneous pool); however, mechanistic models are built on known or assumed biological, chemical, or physical theories (Mertens, 2005), not only on power of statistical analysis. The heterogeneous ruminal fiber pool tested in this research approach has a robust 


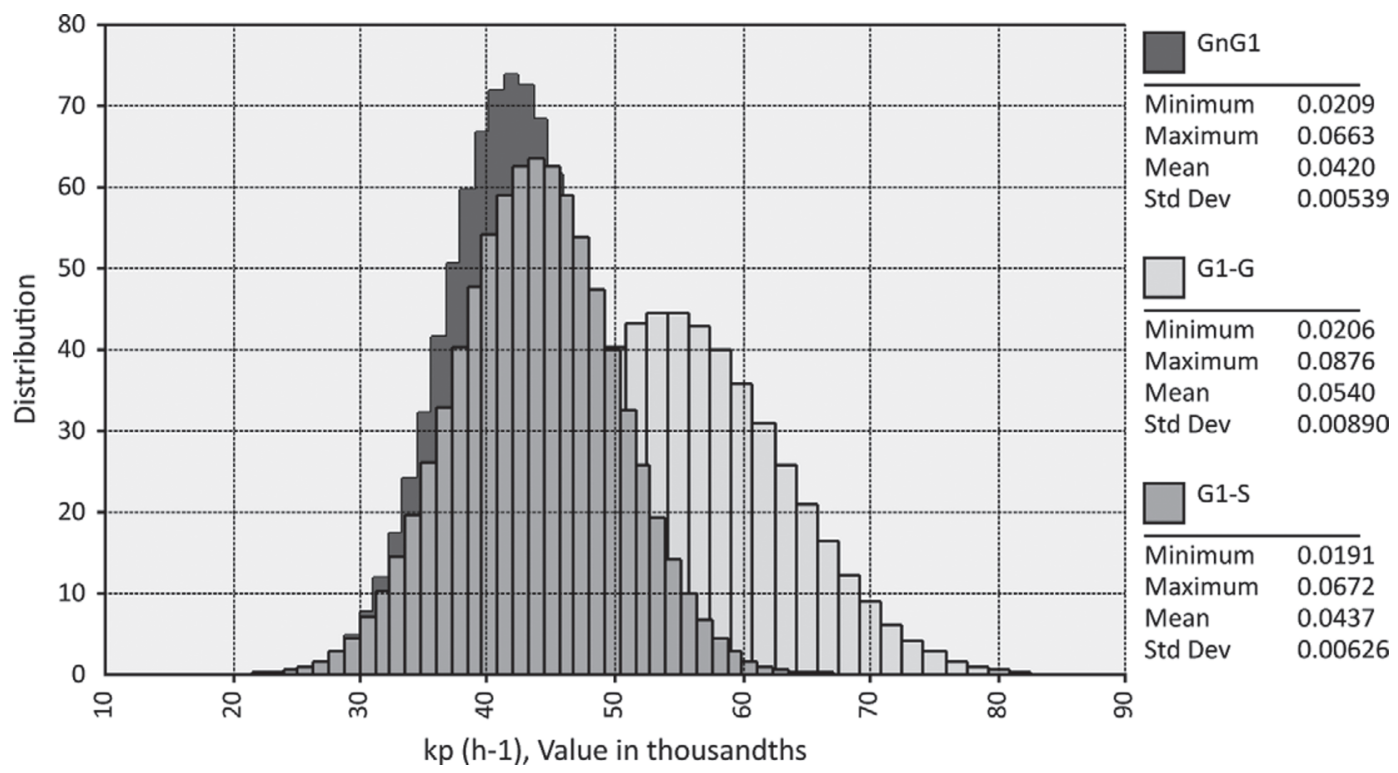

Figure 3. Probability distribution comparison between the 3 equations used to predict the rate of passage $\left(k_{p}\right)$ of forage. All distributions follow a normal pattern. G1-S = scenario using the equations developed by Cannas et al. (2004); G1-G = scenario using the equation developed by Tedeschi et al. (2012); and GnG1 = scenario using the equations developed by Regadas Filho et al. (2014).

mechanistic base, which accounts for known influential factors (Clauss and Lechner-Doll, 2001; Tschuor and Clauss, 2008; Vieira et al., 2008). Thus, its utilization might improve the explanatory power of the SRNS.

\section{Evaluation of the DMI Estimation}

One important consideration must be made regarding the limitation of this evaluation. The DMI observed in these animals is a response to the diet obtained from a specific combination of ingredients. However, the DMI estimated using an optimization technique changes the composition of the diet, so animal performance would be expected to change when using the optimal diet formulated for these specific animals. For a more appropriate assessment of this theory, it is necessary to evaluate this approach from an a priori diet formulation, and then feed the animals and observe their performance (intake and MY). Nevertheless, the results found here were interesting for a first investigative analysis.

The DMI optimization theory seems to be an appropriate technique, if the values predicted with this approach are compared with those based on the empirical regression of AFRC (1993). The DMI acts as an input and output at the same time in each iteration of the model; this creates a loop that reaches the optimum point when the nutrient requirement and diet constraints are achieved.

This approach has an important biological advancement, because predictions are based on nutritional concepts of degradation and passage rates, and they agree in part with the theories of the first-limiting factor and optimization models for estimating DMI, as discussed by Forbes (2007). Moreover, this approach uses the rumen fiber capacity and the nutrient requirement as a modulator of the DMI. The rumen fiber constraint prevents feed intake from exceeding expectations, and the nutrient requirement constraints prevent feed intake below what is needed. The constraints used are considered important nutritional requirements, and some possible dietetic issues were addressed.

The empirical equation adopted by AFRC (1993) does not account for dietary estimation effects; it only considers animal information. This empirical model may cause bias in the estimation when evaluating animals with the same size and level of production but that are fed different feed qualities. On the other hand, the approach evaluated in this paper would yield different DMI estimates for these animals because it considers the intrinsic characteristics of the feed. In addition, the approach to estimate DMI worked well in both scenarios (homogeneous and heterogeneous rumen fiber), and the estimates were independent of the approach used. The best result found with the G1-S model is probably due to the simplicity of its set of equations to estimate the concentrate and forage rate passages when compared with G1-G and GnG1.

The use of the DMI approach in CNCPS-based models depends uniquely on the insertion of this submodel in its set of equations. Given that information on degradation and passage rates are already available in these models, they can be easily used in the process 
of diet optimization. Extra constraints can be added depending on the goal of the user. Obviously, an excess of constraints could limit the applicability of this approach, so users may need to modify the number of constraints to obtain feasible solutions.

The high precision (high $\mathrm{R}^{2}$ ) of the optimization process scenarios indicates high repeatability for the DMI estimation. However, the main problem in using this methodology for formulating ruminant diets is the development of a more appropriate mathematical algorithm to address the hard nonlinearity and interdependence between variables in the model. The nonlinear generalized reduced gradient method (Lasdon et al., 1974) in Excel (version 2010; Microsoft Corp.) was used to solve this problem, and approximately $45 \%$ of the individual runs in each scenario reached a solution (global optimum); however, even when the optimization process did not reach the global optimum, the solution tended to move closer to this point. Many possible methods of optimization can and should be tested (e.g., quasi-Newton method, conjugate gradient method, interior point method) on mechanistic models as the SRNS. Therefore, more accurate DMI estimations are expected when using an algorithm capable of optimizing a vast range of scenarios. Nonetheless, this method seems to be reasonable and can be used in dietary formulations for ruminants.

\section{CONCLUSIONS}

The SRNS model accurately and precisely predicted the MEI for lactating does, regardless of the model used to estimate rumen digestibility. The comparison of the 3 models used to predict rumen digestibility showed that the heterogeneous ruminal fiber approach gave estimates similar to those of single rumen pool models, suggesting its adoption to improve the mechanistic structure and the explanatory power of the SRNS. The lack of information regarding changes in goat BW affected our ability to test the SRNS predictions of MY with the various rumen models tested. The approach for estimating DMI based on the optimization method gave estimates similar to those of the empirical equations and can be used in dietary formulations as it can account for variability in diet quality.

\section{ACKNOWLEDGMENTS}

The scholarship of J. G. L. Regadas Filho was supported by Coordenação de Aperfeiçoamento de Pessoal de Nível Superior (CAPES; Brasilia, Brazil).

\section{REFERENCES}

AFRC (Agricultural and Food Research Council). 1993. Energy and Protein Requirements of Ruminants. An advisory manual prepared by the AFRC Technical Committee on Response to Nutrients. CAB International, Wallingford, UK.

Cannas, A., L. O. Tedeschi, A. S. Atzori, and D. G. Fox. 2007a. The Small Ruminant Nutrition System: Development and evaluation of a goat submodel. Ital. J. Anim. Sci. 6:609-611.

Cannas, A., L. O. Tedeschi, and D. G. Fox. 2007b. Prediction of metabolizable energy intake and energy balance of goats with the Small Ruminant Nutrition System. Pages 569-570 in Proc. 2nd Int. Symp. Energy and Protein Metabolism and Nutrition, Vichy, France. Wageningen Academic Publishers, Wageningen, the Netherlands.

Cannas, A., L. O. Tedeschi, D. G. Fox, A. N. Pell, and P. J. Van Soest. 2004. A mechanistic model for predicting the nutrient requirements and feed biological values for sheep. J. Anim. Sci. $82: 149-169$.

Clauss, M., and M. Lechner-Doll. 2001. Differences in selective reticulo-ruminal particle retention as a key factor in ruminant diversification. Oecologia 129:321-327.

Demment, M. W., and P. J. Van Soest. 1985. A nutritional explanation for body-size patterns of ruminant and nonruminant herbivores. Am. Nat. 125:641-672.

Forbes, J. M. 2007. A personal view of how ruminant animals control their intake and choice of food: Minimal total discomfort. Nutr. Res. Rev. 20:132-146.

Fox, D. G., L. O. Tedeschi, T. P. Tylutki, J. B. Russell, M. E. Van Amburgh, L. E. Chase, A. N. Pell, and T. R. Overton. 2004. The Cornell Net Carbohydrate and Protein System model for evaluating herd nutrition and nutrient excretion. Anim. Feed Sci. Technol. 112:29-78.

Illius, A. W., and I. J. Gordon. 1991. Prediction of intake and digestion in ruminants by a model of rumen kinetics integrating animal size and plant characteristics. J. Agric. Sci. 116:145-157.

Lanzas, C., C. J. Sniffen, S. Seo, L. O. Tedeschi, and D. G. Fox. 2007. A revised CNCPS feed carbohydrate fractionation scheme for formulating rations for ruminants. Anim. Feed Sci. Technol. 136:167-190.

Lasdon, L. S., R. L. Fox, and M. W. Ratner. 1974. Nonlinear optimization using the generalized reduced gradient method. Recherche Opérationnelle 8:73-103.

Matis, J. H. 1972. Gamma time-dependency in Blaxter's compartmental model. Biometrics 28:597-602.

Mertens, D. R. 2005. Rate and extend of digestion. Pages 13-47 in Quantitative Aspects of Ruminant Digestion and Metabolism. 2nd ed. J. Dijkstra, J. M. Forbes, and J. France, ed. CAB International, Wallingford, UK.

NRC. 2007. Nutrient Requirements of Small Ruminants: Sheep, Goats, Cervids, and New World Camelids. 6th ed. Natl. Acad. Press, Washington, DC.

Poppi, D. P., M. Gill, and J. France. 1994. Integration of theories of intake regulation in growing ruminants. J. Theor. Biol. 167:129145 .

Regadas Filho, J. G. L., L. O. Tedeschi, R. A. M. Vieira, and M. T. Rodrigues. 2014. Assessment of the heterogeneous ruminal fiber pool and development of a mathematical approach for predicting the mean retention time of feeds in goats. J. Anim. Sci. 92:10991109.

Sniffen, C. J., J. D. O'Connor, P. J. Van Soest, D. G. Fox, and J. B. Russell. 1992. A net carbohydrate and protein system for evaluating cattle diets: II. Carbohydrate and protein availability. J. Anim. Sci. 70:3562-3577.

Sutherland, T. M. 1988. Particle Separation in the Forestomach of Sheep. Pages 43-73 in Aspects of Digestive Physiology in Ruminants. A. Dobson and M. J. Dobson, ed. Comstock Publ. Associates, Ithaca, NY. 
Tedeschi, L. O. 2006. Assessment of the adequacy of mathematical models. Agric. Syst. 89:225-247.

Tedeschi, L. O., A. Cannas, and D. G. Fox. 2010. A nutrition mathematical model to account for dietary supply and requirements of energy and other nutrients for domesticated small ruminants: The development and evaluation of the Small Ruminant Nutrition System. Small Rumin. Res. 89:174-184.

Tedeschi, L. O., A. Cannas, S. G. Solaiman, R. A. M. Vieira, and N. K. Gurung. 2012. Development and evaluation of empirical equations to predict ruminal fractional passage rate of forages in goats. J. Agric. Sci. 150:95-107.

Tschuor, A., and M. Clauss. 2008. Investigations on the stratification of forestomach contents in ruminants: An ultrasonographic approach. Eur. J. Wildl. Res. 54:627-633.
Tylutki, T. P., D. G. Fox, V. M. Durbal, L. O. Tedeschi, J. B. Russell, M. E. Van Amburgh, T. R. Overton, L. E. Chase, and A. N. Pell 2008. Cornell Net Carbohydrate and Protein System: A model for precision feeding of dairy cattle. Anim. Feed Sci. Technol. 143:174-202.

Van Soest, P. J. 1994. Nutritional Ecology of the Ruminant. 2nd ed. Cornell University Press, Ithaca, NY.

Vieira, R. A., L. Tedeschi, and A. Cannas. 2008. A generalized compartmental model to estimate the fibre mass in the ruminoreticulum: 2. Integrating digestion and passage. J. Theor. Biol. 255:357-368.

Waldo, D. R., L. W. Smith, and E. L. Cox. 1972. Model of cellulose disappearance from the rumen. J. Dairy Sci. 55:125-129. 